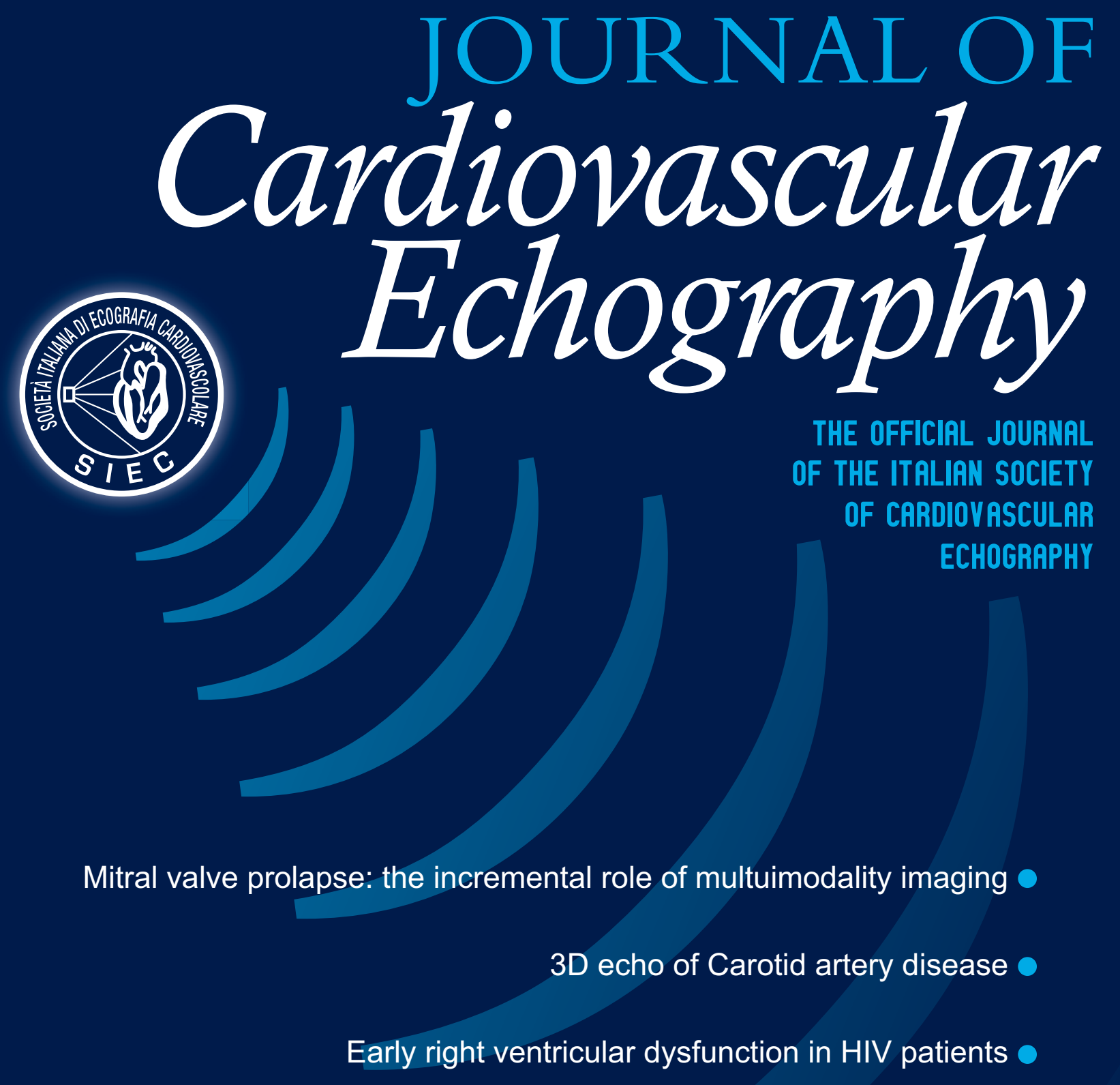




\title{
Early Right Ventricular Dysfunction in Highly Selected (Totally Free from Cardiovascular Risk Factors and Other Comorbidities) Human Immunodeficiency Virus Patients: A Pilot Study with Advanced Echocardiography
}

\author{
Martino Deidda, Christian Cadeddu Dessalvi, Selina Campus, Francesco Ortu, Paolo Piano, Pier Paolo Bassareo, Giuseppe Mercuro \\ Department of Medical Sciences and Public Health, University of Cagliari, Monserrato, Italy
}

\section{Abstract}

Objective: Human immunodeficiency virus (HIV) infection may also be associated with cardiac dysfunction, thus negatively affecting patients' morbidity and mortality. This preliminary study aimed at evaluating whether bi-and three-dimensional (3D) strain echocardiographic facilities were able to identify alterations in the right ventricular (RV) function in highly selected - because free from cardiovascular risk factors and other comorbidities - HIV patients. Materials and Methods: Eight of these specific HIV patients (age: $32.0 \pm 3.6$ years; 7 months) treated with highly active antiretroviral therapy (HAART) were enrolled and compared with 8 sex-, age-, and cardiovascular risk profile-matched healthy individuals. All underwent clinical evaluation and transthoracic echocardiography coupled with tissue Doppler, two-dimensional (2D), and 3D speckle tracking imaging to examine their RV function. Results: All standard echocardiographic parameters resulted in the normal range, with no significant differences between HIV and controls. On the contrary, 2D longitudinal strain $(16.1 \% \pm 1.6 \%$ vs. $17.8 \% \pm 0.9 \%, P=0.02)$ and Global 3D strain $(28.5 \% \pm 3.6 \%$ vs. $33.5 \% \pm 1.9 \%, P=0.0002)$ were reduced in the HIV group. Moreover, Global 3D strain values showed a direct correlation with RV fractional area change values $(r=0.66, P=0.005)$. Conclusions: 2D longitudinal and 3D Global strain can identify an early asymptomatic RV impairment in HIV patients free from other risk factors and comorbidities. These findings seem to imply that also in treated with HAART and well-controlled HIV patients an early asymptomatic systolic RV dysfunction is present, as a distinctive and separated pathological entity compared with classic HIV-related pulmonary arterial hypertension and left ventricular dysfunction. In these patients, RV dysfunction is not revealed by standard echocardiography.

Keywords: Highly active antiretroviral therapy, human immunodeficiency virus, right ventricular function, speckle tracking echocardiography, three-dimensional echocardiography

\section{INTRODUCTION}

Several reports in literature highlighted a strong association between human immunodeficiency virus (HIV) infection and cardiac diseases, which increases patients' morbidity and mortality. HIV itself, as well as autoimmune response, and usual HIV patients high cardiovascular risk profile are the main causes leading together to cardiac dysfunction, ${ }^{[1]}$ whose variable clinical expression depends on many factors, namely disease stage, degree of immunodeficiency, administration of anti-HIV drugs, and associated opportunistic infections and malignancies. ${ }^{[2]}$ Dilated cardiomyopathy with left ventricular dysfunction is one of the most common HIV-related

\section{Access this article online}

\section{Quick Response Code:}

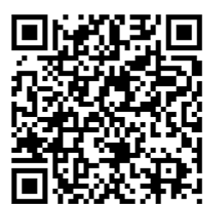

Website:

www.jcecho.org

DOI:

10.4103/jcecho.jcecho_43_18 cardiovascular complications (around $30 \%$ of the patients). $[2,3]$ An isolated and reversible right ventricular (RV) dysfunction, often coupled with pulmonary arterial hypertension, was identified as well $(10 \%-30 \%))^{[4,5]}$ Since it is linked to increased mortality in the setting of many cardiovascular diseases, ${ }^{[6]}$ several studies on cardiac RV impairment in HIV patients

Address for correspondence: Dr. Pier Paolo Bassareo Department of Medical Sciences and Public Health, University of Cagliari, SS Sestu KM 0.700, 09042 Monserrato (CA), Italy. E-mail: piercard@inwind.it

This is an open access journal, and articles are distributed under the terms of the Creative Commons Attribution-NonCommercial-ShareAlike 4.0 License, which allows others to remix, tweak, and build upon the work non-commercially, as long as appropriate credit is given and the new creations are licensed under the identical terms.

For reprints contact: reprints@medknow.com

How to cite this article: Deidda M, Dessalvi CC, Campus S, Ortu F, Piano P, Bassareo PP, et al. Early right ventricular dysfunction in highly selected (totally free from cardiovascular risk factors and other comorbidities) human immunodeficiency virus patients: A pilot study with advanced echocardiography. J Cardiovasc Echography 2018;28:228-32. 
were carried out; however, only few evaluated the subclinical abnormalities in participants with well-controlled viral and immunological state..$^{[7]}$

This pilot study aimed at analyzing the RV function in HIV patients, in optimal clinical conditions (including normal left ventricular function and pulmonary arterial pressures [PAPs]) and free from traditional cardiovascular risk factors, using standard and advanced echocardiographic techniques (such as speckle tracking and 3D-echocardiography). Results were compared to those from healthy controls.

\section{Materials and Methods}

\section{Population in the study}

Eight HIV participants ( 7 males and 1 female) were selected over the 354 followed at the University of Cagliari. They were compared to eight healthy peers.

The following inclusion criteria were adopted: HIV infection; age range $18-50$ years.

Exclusion criteria were as follows: ongoing or previous drug abuse, presence of opportunistic infections or tumors, existing cardiovascular diseases, or risk factors (familial history, smoking, diabetes, dyslipidemia, and hypertension). The decidedly strict criteria of inclusion/exclusion lead to recruit only $2.2 \%$ of the sample. Patients' clinical and laboratory characteristics, collected from medical records review and participants' individual interviews, are summarized in Table 1, Panel A.

According to the centers for disease control and prevention criteria, at HIV first diagnosis, one patient was in clinical Stage A1, four in Stage A2, two in Stage B2, and one in Stage C3. The average time from the first diagnosis was 72 months (range 22-2). All the selected patients were treated with highly active antiretroviral therapy (HAART), i.e., a combination of at least three drugs, for a mean time of 5.8 years (range 2-22). The infection was transmitted by sexual contact in seven patients (two heterosexual and five homosexual participants) and in one case by vertical transmission.

The study was approved by the Institutional Ethics Committee (PG/2015/1859) and conducted in accordance with the Declaration of Helsinki. All enrolled participants gave their informed written consent.

\section{Laboratory data}

In all HIV patients, viremia was suppressed ( $\leq 50$ copies $/ \mathrm{ml})$. CD4+ showed optimal levels in all the patients, confirming good adherence to HAART, which proves to be effective for values $>500$ cell $/ \mu$ l (mean: $684 \pm 25$ cells $/ \mathrm{uL}$ ).

\section{Standard echocardiography}

A commercial system (Toshiba Artida-Toshiba Corp., Tochigi, Japan) equipped with tissue Doppler imaging (TDI) and speckle tracking facilities was used. Left ventricular ejection fraction (EF) (modified Simpson's biplane method), E/A

\begin{tabular}{|c|c|c|}
\hline Panel A: Clinical data & HIV patients $(n=8)$ & Controls $(n=8)$ \\
\hline Age (year) & $32 \pm 3.5$ & $32.7 \pm 6.2$ \\
\hline Sex & $7 \hat{\delta}-1$ 우 & $7 \hat{\delta}-1$ 우 \\
\hline Height (mt) & $1.70 \pm 8.0$ & $1.72 \pm 10.6$ \\
\hline Weight (kg) & $67.4 \pm 6.3$ & $71.1 \pm 8.2$ \\
\hline $\operatorname{BSA}\left(\mathrm{m}^{2}\right)$ & $1.8 \pm 0.1$ & $1.8 \pm 0.2$ \\
\hline BMI $\left(\mathrm{kg} / \mathrm{m}^{2}\right)$ & $23.2 \pm 0.6$ & $23.9 \pm 0.5$ \\
\hline Familiar history & - & - \\
\hline Hypertension & - & - \\
\hline Dyslipidemia & - & - \\
\hline Diabetes & - & - \\
\hline Smoking & - & - \\
\hline NRTI + PI $(n)$ & 2 & - \\
\hline $\mathrm{PI}(n)$ & 1 & - \\
\hline NRTI + NNRTI $(n)$ & 5 & - \\
\hline $\operatorname{GFR}(\mathrm{ml} / \mathrm{min})$ & 89,12 & 90,37 \\
\hline $\begin{array}{l}\text { Total cholesterolemia } \\
(\mathrm{mg} / \mathrm{dl})\end{array}$ & $<200$ & $<200$ \\
\hline C-reactive protein $(\mathrm{mg} / \mathrm{L})$ & 5 & 4 \\
\hline $\operatorname{ESR}(\mathrm{mm})$ & 5 & 7 \\
\hline HBV RNA & Negative & Negative \\
\hline HCV RNA & Negative & Negative \\
\hline HIV RNA (copies/ml) & $<50$ & - \\
\hline $\mathrm{CD} 4+(\%)$ & $28 \%$ & - \\
\hline $\mathrm{CD} 4+(\operatorname{cell} / \mu 1)$ & $684 \pm 25$ & - \\
\hline Panel B & \multicolumn{2}{|c|}{ LV echocardiographic data } \\
\hline EDD (mm) & $46.5 \pm 2.8$ & $47.2 \pm 3.0$ \\
\hline IVS (mm) & $8.4 \pm 0.8$ & $8.8 \pm 0.9$ \\
\hline $\mathrm{PW}(\mathrm{mm})$ & $7.9 \pm 0.9$ & $8.7 \pm 1.1$ \\
\hline LAVI $\left(\mathrm{ml} / \mathrm{m}^{2}\right)$ & $24.7 \pm 5.5$ & $25.0 \pm 2.6$ \\
\hline $\mathrm{EF}(\%)$ & $64.2 \pm 3.1$ & $62.5 \pm 2.8$ \\
\hline $\mathrm{S}(\mathrm{cm} / \mathrm{s})$ & $9.4 \pm 1.4$ & $8.3 \pm 0.6$ \\
\hline $\mathrm{E} / \mathrm{A}$ & $1.6 \pm 0.4$ & $1.6 \pm 0.3$ \\
\hline$E^{\prime} / A^{\prime}$ & $1.5 \pm 0.2$ & $1.6 \pm 0.4$ \\
\hline $\mathrm{E} / \mathrm{E}$ & $6.0 \pm 1.2$ & $6.0 \pm 1.0$ \\
\hline Panel C & \multicolumn{2}{|c|}{ RV echocardiographic data } \\
\hline $\mathrm{EDD}(\mathrm{mm})$ & $34.0 \pm 3.0$ & $32.0 \pm 2.0$ \\
\hline TAPSE (mm) & $22.0 \pm 5.0$ & $24.0 \pm 3.0$ \\
\hline TEI index (mm) & $0.2 \pm 0.0$ & $0.2 \pm 0.0$ \\
\hline Right atrium area $\left(\mathrm{cm}^{2}\right)$ & $13.7 \pm 3.6$ & $14.4 \pm 1.7$ \\
\hline FAC $(\%)$ & $50.5 \pm 4.3$ & $54.4 \pm 6.3$ \\
\hline $\mathrm{S}^{\prime}(\mathrm{cm} / \mathrm{s})$ & $14.2 \pm 0.9$ & $14.0 \pm 0.7$ \\
\hline $\mathrm{E} / \mathrm{A}$ & $1.5 \pm 0.2$ & $1.6 \pm 0.2$ \\
\hline$E^{\prime} / A^{\prime}$ & $1.1 \pm 0.3^{*}$ & $1.5 \pm 0.2$ \\
\hline $\mathrm{E} / \mathrm{E}^{\prime}$ & $6.1 \pm 3.3$ & $5.8 \pm 0.9$ \\
\hline PAPs (mmHg) & $26.0 \pm 2.0$ & $25.0 \pm 4.0$ \\
\hline $\begin{array}{l}\text { o means MALES, whi } \\
\text { controls. BSA=Body } \\
\text { PI=Protease inhibitors, } \\
\text { Inhibitors, NNRTI=NonN } \\
\text { GFR=Glomerular filtratio } \\
\text { IVS=Inter-ventricular sep } \\
\text { volume index, EF=Ejectic } \\
\text { and Atrial peak velocity, E } \\
\text { Anular Plane Systolic Exc } \\
\text { S wave peak velocity, E'/ } \\
\text { peak velocity, E/E'=Ratio } \\
\text { TDI=Tissue Doppler imag } \\
\text { immunodefi ciency vi } \\
\text { HCV=Hepatitis C virus, H }\end{array}$ & $\begin{array}{l}\text { P means FEMALEs } \\
\text { rface area, BMI=Bc } \\
\text { NRTI=Nucleoside Rev } \\
\text { cleoside Reverse Trans } \\
\text { rate, ESR=erythrocyte } \\
\mathrm{m}, \mathrm{PW}=\text { Posterior wall, } \\
\text { fraction, E/A=Ratio bc } \\
\mathrm{D}=\text { End diastolic diamete } \\
\text { sion, FAC=Fractional A } \\
=\text { Ratio between TDI Ear } \\
\text { tween E wave at PWD } \\
\text { g, PWD=Pulsed wave D } \\
\mathrm{s}, \mathrm{PAPs}=\text { Pulmonary } \\
\mathrm{V}=\text { Hepatitis B virus }\end{array}$ & $\begin{array}{l}* P=0.02 \text { versus } \\
\text { y mass index, } \\
\text { se Transcriptase } \\
\text { riptase Inhibitors, } \\
\text { edimentation rate, } \\
\text { LAVI=Left atrium } \\
\text { ween Early filling } \\
\text { TAPSE=Tricuspid } \\
\text { a Change, } S \text { '=TDI } \\
\text { fi lling and Atrial } \\
\text { id E' wave at TDI, } \\
\text { pler, HIV=Human } \\
\text { rterial pressures, }\end{array}$ \\
\hline
\end{tabular}


ratio, TDI peak systolic (S'), early diastolic $\left(E^{\prime}\right)$, and late diastolic $\left(\mathrm{A}^{\prime}\right)$ were measured.

\section{Right ventricular function}

Its study is considerable more difficult than that of the left ventricle. According to the most recent recommendations, ${ }^{[8]}$ RV end-diastolic (RVEDA) and end-systolic (ESA) areas, RV fractional area change $(F A C)($ RVFAC $=[[$ RVEDA-RVESA $] /$ RVE-DA] $\times 100$ ), peak PAPs, tricuspid annular systolic plane excursion (TAPSE), and RV myocardial performance index were calculated. Strain analysis was performed by tracking the endocardial RV surface in the apical four-chamber view with a point-and-click approach. The second larger concentric border was automatically generated and manually adjusted near the epicardium. ${ }^{[8]}$

3D transthoracic echocardiography was performed at the cardiac apex, with subjects lying in the left lateral position. Full-volume images were acquired over three consecutive cardiac cycles. A wide sector of $90^{\circ} \times 90^{\circ}$ was used to ensure inclusion of the entire RV inflow and body cavity in the $3 \mathrm{D}$ full-volume data set. ${ }^{[8]}$ The frame rate ranged from 18 to 25 volumes/s. All echocardiographic recordings were stored in an external hard disk for offline analysis (Advanced Cardiology Package; Toshiba Medical Systems). On the basis of the 3D volume data-set, a five-plane evaluation that included the RV apical four-chamber view, two-chamber orthogonal view, and three short-axis views (at the apex, middle level, and base of the ventricle) were displayed. On the basis of these five views, the RV endocardial border was traced, and its movements during cardiac systole and diastole were automatically tracked to calculate global and regional area strain ${ }^{[8]}$ From global and regional time-strain curves, the RV global peak area strain was determined. ${ }^{[8]}$

\section{Statistics}

Non-parametric Mann-Whitney U-test for noncontinuous variables; Chi-square test for continuous variables; univariate analysis, Pearson correlation coefficients, and regression lines for relationships between the various parameters; multivariate analysis was not applied because of the small sample size; and minimum level of statistical significance: $P<0.05$ (software SPSS version 22.0, SPSS Inc., Chicago, Illinois, USA).

\section{RESULTS}

Standard echocardiography and TDI: no statistically significant differences in both left ventricle and RV values [Table 1, Panels B and C].

\section{Speckle tracking echocardiography and three-dimensional echocardiography}

The RV longitudinal strain values were significantly reduced in the HIV patients compared to controls $(P<0.001)$, while the strain rate, despite higher values in healthy participants, resulted not significantly reduced $(P=0.17)$, probably due to the small sample size [Figure 1].
The Global 3D strain was lower in HIV patients than in healthy controls [Figure 2] and showed a direct statistically significant correlation with FAC values $[r=0.65, P=0.005$; Figure 3]. The observed reductions in RV longitudinal strain and Global 3D strain are relative, rising from the significant differences between values in HIV group versus those in healthy controls.

\section{Discussion}

Our work was conducted only on high-selected HIV patients, i.e., without cardiovascular diseases and risk factors for developing heart disease, as confirmed by their clinical and instrumental evaluations. In addition, they presented positivity to serology for HIV with good immunological status and suppressed viremia.

Many literature reports highlighted the presence of an early RV involvement in HIV patients, which may be isolated or coupled with a previous impairment in left ventricular function..$^{[9,10]}$ More recently, at advanced echo, it was demonstrated a reduction in RV systolic function parameters in more than a tenth of participants particularly at longitudinal strain. ${ }^{[4]}$

In this study, all conventional systolic RV function parameters (TAPSE; S' wave at tricuspid annulus) and PAPs were normal in both groups. However, the highly-selected HIV patients were characterized by a reduction in RV myocardial deformation indices as measured by advanced echocardiography (speckle tracking). In these individuals, their subtle RV dysfunction seems to be a distinctive and separated pathological entity compared with classic HIV-related pulmonary arterial hypertension and left ventricular dysfunction since of the normality of these two, as reported in Table 1.

The study of myocardial deformation parameters is more sensitive than traditional indexes. In a recently published comprehensive review, all the echo parameters useful in RV anatomical and functional assessment where analyzed in detail including those of myocardial deformation (strain and strain rate) and those obtained by 3D-echocardiography. The latter was considered the most promising technique in identifying a subclinical RV dysfunction. ${ }^{[11]}$ When comparing 2D and 3D echocardiography in the study of RV function with data obtained by cardiac magnetic resonance imaging (MRI), 3D echo proves to be able to assess both RV anatomy and function with good sensitivity and specificity. ${ }^{[12]}$

In our population, the reduction in both 2D longitudinal strain and 3D Global strain values seems to indicate a subclinical impairment in RV systolic function even in patients with still normal conventional echocardiographic parameters. In addition, the Global 3D strain showed a direct correlation with the FAC, one of the most reliable echocardiographic parameters in evaluating RV systolic function for its closely correlation with the EF measured with gold standard techniques.

Criteria of inclusion in this study were particularly strict as testified by the excellent HIV infection control, which 

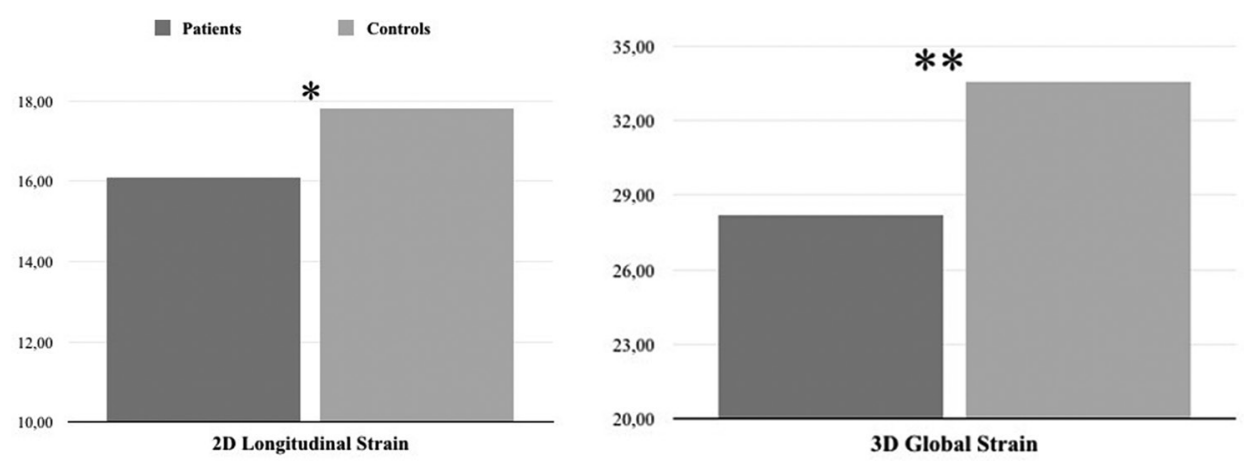

Figure 1: Two-dimensional longitudinal and three-dimensional global strain of the right ventricle $\left({ }^{\star} P<0.05 ;{ }^{*} P<0.001\right)$

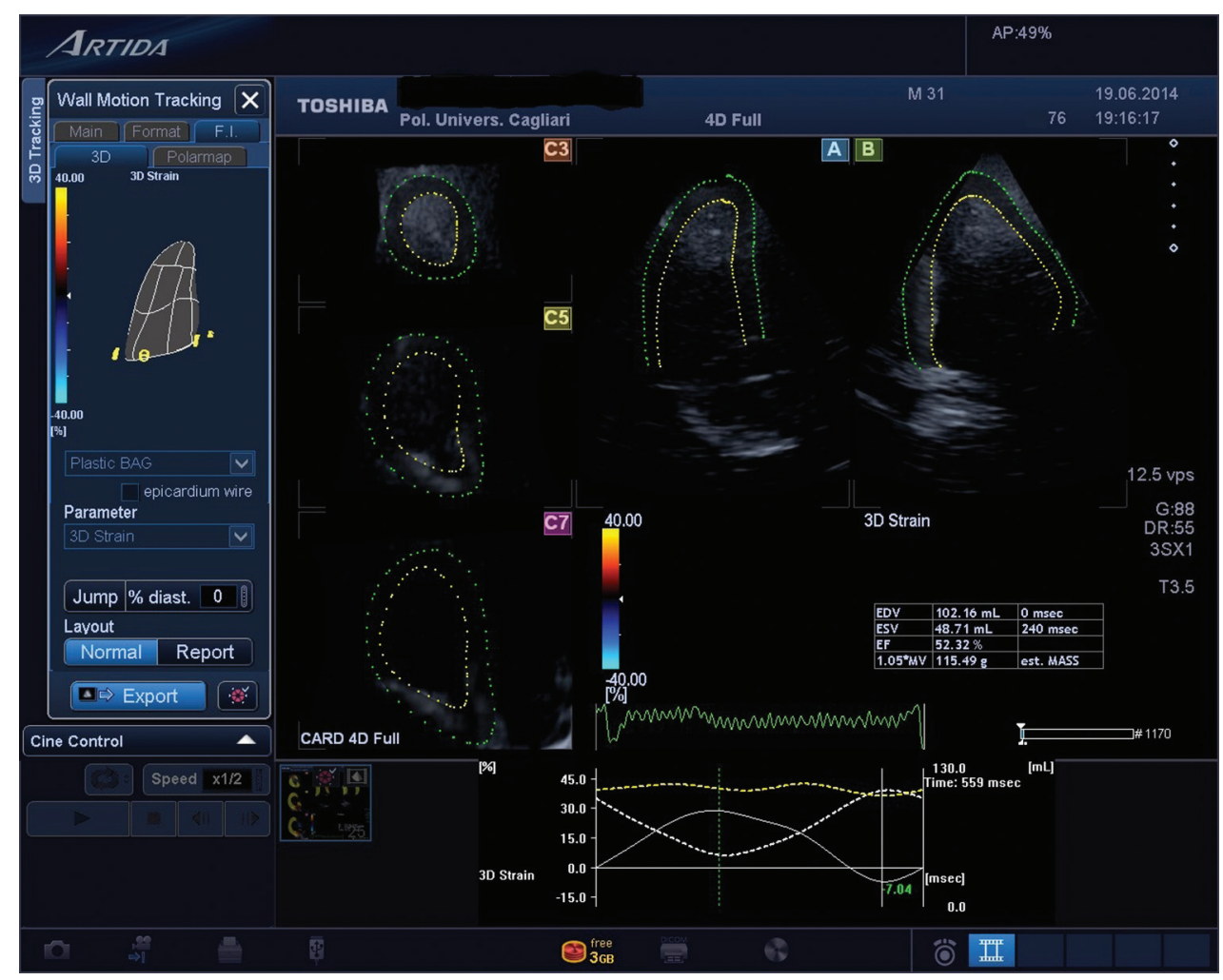

Figure 2: Measurement of three-dimensional global strain at right ventricle

was confirmed by suppressed viral load, CD4+ cells count, and normal inflammatory indexes. Therefore, it would be hypothesized that also when excluding cardiovascular risk factors and/or diseases and/or malignancies and when AIDS is well controlled, HIV infection, and/or HAART can determine a subclinical impairment in RV function.

The pathophysiological mechanisms of myocardial damage in the course of HIV infection are well described in literature: a direct action of the virus, such as in viral myocarditis, involvement of proteins such as GP120, capable of determining a dysregulation in autophagy processes, thus altering cardiomyocytes function; proinflammatory cytokines stimulated by the chronic infection, whose direct action may have a negative inotropic action; induction of cardiomyocytes apoptosis by iNOS excessive activation, a component of the immune response previously demonstrated in myocarditis and dilated cardiomyopathy. ${ }^{[13]}$

On the other hand, it is known that HAART itself can induce cardiovascular diseases through various mechanisms, the most known of whom is related to an accelerated atherogenesis. ${ }^{[1,14]}$ However, the particular characteristics of the enrolled population seem to exclude a similar pathogenesis. It is likely the involvement of mechanisms other than atherosclerosis. In this respect, in HAART patients, we had previously demonstrated the presence of subclinical alterations in left ventricular systolic function, depending on the class of administered antiretroviral agents. ${ }^{[15]}$ Other studies are needed to better clarify this interesting issue.

The main limitation of this pilot study, i.e., the small sample size, is also its strength because the research focuses only on 


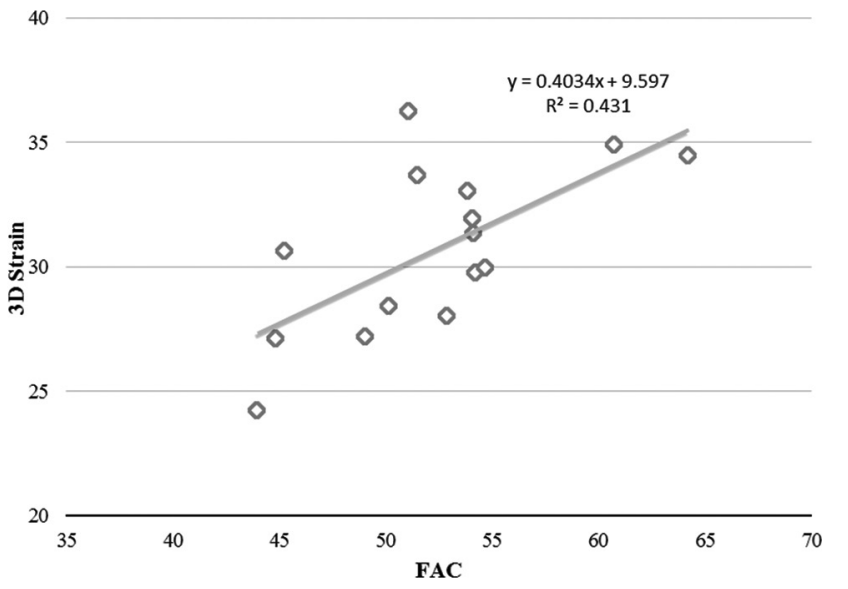

Figure 3: Correlation between three-dimensional global strain and fractional area change

a very homogeneous population. All the possible confounding factors were eliminated beforehand. On the other hand, the examined patients were (and still are) the only available with the suitable characteristics in our university. Although we are looking for increasing the numerosity of the sample, it is likely to require years. Furthermore, as echocardiographic RV function assessment still represents a challenge despite rapid improvement in imaging facilities, other reliable parameters might have been used. ${ }^{[16]}$ For example, an undoubtedly useful measurement, such as RV 3D EF, was not calculated because the commercial software that we used had not been previously validated to do that. We chose to seek possible correlations with $\mathrm{FAC}$, as according to guidelines, it is a measure of RV systolic function that was shown to correlate with RV EF by MRI. RV FAC was found to be an independent predictor of heart failure, sudden death, stroke, and/or mortality in studies of patients after pulmonary embolism and myocardial infarction. ${ }^{[17]}$ Finally, we chose to include the interventricular septum in 2D strain evaluation and not only the free wall, although it is more validated. The reason why we did so was to increase the uniformity between 2D and 3D global strain measurements.

\section{Conclusions}

2D longitudinal and 3D Global strain are able to identify an early asymptomatic RV impairment in HIV patients free from cardiovascular risk factors and comorbidities, treated with HAART, and well-controlled. This dysfunction, although not revealed by standard echocardiography, is detectable by means of advanced facilities such as 2D and 3D speckle tracking imaging. A possible direct cardiotoxic effect due to HIV infection itself and/or HAART was suggested. A more careful cardiovascular follow-up even in these apparently less vulnerable HIV patients is undoubtedly needed.

\section{Financial support and sponsorship}

Nil.

\section{Conflicts of interest}

There are no conflicts of interest.

\section{References}

1. Kaplan RC, Hanna DB, Kizer JR. Recent insights into cardiovascular disease (CVD) risk among HIV-infected adults. Curr HIV/AIDS Rep 2016;13:44-52.

2. Khunnawat C, Mukerji S, Havlichek D Jr., Touma R, Abela GS. Cardiovascular manifestations in human immunodeficiency virus-infected patients. Am J Cardiol 2008;102:635-42.

3. Sudano I, Spieker LE, Noll G, Corti R, Weber R, Lüscher TF, et al. Cardiovascular disease in HIV infection. Am Heart J 2006;151:1147-55.

4. Simon MA, Lacomis CD, George MP, Kessinger C, Weinman R, McMahon $\mathrm{D}$, et al. Isolated right ventricular dysfunction in patients with human immunodeficiency virus. J Card Fail 2014;20:414-21.

5. Casalino E, Laissy JP, Soyer P, Bouvet E, Vachon F. Assessment of right ventricle function and pulmonary artery circulation by cine-MRI in patients with AIDS. Chest 1996;110:1243-7.

6. Ghio S, Gavazzi A, Campana C, Inserra C, Klersy C, Sebastiani R, et al. Independent and additive prognostic value of right ventricular systolic function and pulmonary artery pressure in patients with chronic heart failure. J Am Coll Cardiol 2001;37:183-8.

7. Rangasetty UC, Rahman AM, Hussain N. Reversible right ventricular dysfunction in patients with HIV infection. South Med J 2006;99:274-8.

8. Lang RM, Badano LP, Mor-Avi V, Afilalo J, Armstrong A, Ernande L, et al. Recommendations for cardiac chamber quantification by echocardiography in adults: An update from the American Society of Echocardiography and the European Association of Cardiovascular imaging. J Am Soc Echocardiogr 2015;28:1-39.e14.

9. Lebech AM, Gerstoft J, Hesse B, Petersen CL, Kjaer A. Right and left ventricular cardiac function in a developed world population with human immunodeficiency virus studied with radionuclide ventriculography. Am Heart J 2004;147:482-8.

10. Karavidas A, Tsiachris D, Lazaros G, Xylomenos G, Arapi S, Potamitis N, et al. Doppler tissue imaging unmasks right ventricular function abnormalities in HIV-infected patients. Cardiol J 2010;17:587-93.

11. Kasprzak JD, Huttin O, Wierzbowska-Drabik K, Selton-Suty C. Imaging the right heart-pulmonary circulation unit: The role of ultrasound. Heart Fail Clin 2018;14:361-76.

12. van der Zwaan HB, Geleijnse ML, McGhie JS, Boersma E, Helbing WA, Meijboom FJ, et al. Right ventricular quantification in clinical practice: Two-dimensional vs. three-dimensional echocardiography compared with cardiac magnetic resonance imaging. Eur $\mathrm{J}$ Echocardiogr 2011;12:656-64.

13. Hidalgo JA, MacArthur RD, Crane LR. An overview of HIV infection and AIDS: Etiology, pathogenesis, diagnosis, epidemiology, and occupational exposure. Semin Thorac Cardiovasc Surg 2000;12:130-9.

14. Sani MU. Myocardial disease in human immunodeficiency virus (HIV) infection: A review. Wien Klin Wochenschr 2008;120:77-87.

15. Mercuro G, Cadeddu C, Nocco S, Deidda M, Mercuro S, Piano P, et al. Subclinical contractility impairment in HIV-infected patients: Dependence on the class of antiretroviral drugs. Int $\mathrm{J}$ Cardiol 2013;168:1538-9.

16. Allam LE, Onsy AM, Ghalib HA. Right ventricular outflow tract systolic excursion and fractional shortening: Can these echocardiographic parameters be used for the assessment of right ventricular function? J Cardiovasc Echogr 2017;27:52-8.

17. Rudski LG, Lai WW, Afilalo J, Hua L, Handschumacher MD, Chandrasekaran $\mathrm{K}$, et al. Guidelines for the echocardiographic assessment of the right heart in adults: A report from the American Society of Echocardiography endorsed by the European Association of Echocardiography, a registered branch of the European Society of Cardiology, and the Canadian Society of Echocardiography. J Am Soc Echocardiogr 2010;23:685-713. 